To Cite: Bucurgat M, 2021. Voltage Dependent Barrier Height, Ideality Factor and Surface States in Au/(NiS-PVP)/n-Si (MPS) type Schottky Barrier Diodes. Journal of the Institute of Science and Technology, 11(2): 1058-1067.

\title{
Voltage Dependent Barrier Height, Ideality Factor and Surface States in Au/(NiS-PVP)/n-Si
} (MPS) type Schottky Barrier Diodes

\section{Mahmut BUCURGAT ${ }^{1 *}$}

\begin{abstract}
Metal-Polymer-Semiconductor (MPS) Schottky Barrier Diodes (SBD) were manufactured and their basic electrical parameters were obtained by the measurement of the forward and reverse bias current-voltage $(\mathrm{I}-\mathrm{V})$ in the wide bias voltage range $( \pm 3 \mathrm{~V})$ to determine the voltage dependent effects on Nickel-Sulphur (NiS) doped Poly Vinyl Pyrrolidone (PVP) polymer interlayer. The saturation current $\left(\mathrm{I}_{0}\right)$, zero-bias barrier height $\left(\Phi_{\mathrm{B} 0}\right)$, rectifying rate $(\mathrm{RR})$, ideality factor $(\mathrm{n})$ and the real value of series - shunt resistances (Rs - Rsh) were calculated. The voltage dependent profile of $\mathrm{n}(\mathrm{V}), \Phi_{\mathrm{B}}(\mathrm{V})$, and Rs $(\mathrm{V})$ were derived. The forward bias $\ln$ I-V plot of the MPS type SBD indicates a good rectifier behaviour and it has two distinctive linear parts with different slopes which correspond to low $(0.288 \leq \mathrm{V} \leq 0.625 \mathrm{~V})$ and moderate $(0.672 \leq \mathrm{V} \leq 0.960 \mathrm{~V})$ bias voltages and then deviates from linearity due to Rs and interlayer at high forward bias voltages. Energy dependent profile of Nss was obtained from the forward bias I-V data by considering voltage dependent barrier height $\left(\Phi_{\mathrm{B}}\right)$ and $\mathrm{n}$. Nss plot represents U-shape behaviour in the forbidden bandgap. The mean value of Nss was found at about $7.0 \times 10^{12} \mathrm{eV}^{-1} \mathrm{~cm}^{-2}$ and this value is in the acceptable limit for a semiconductor device and such lower values of Nss are the consequences of the passivation effect on the surface states.
\end{abstract}

Keywords: MPS type SBD, Voltage dependent barrier height, Series resistance, Surface states, Double exponential $I-V$ behavior 


\section{INTRODUCTION}

The electrical and optical behaviours of metal-semiconductor (MS) junction with or without an interlayer such as insulator/oxide, polymer or its composites (MIS/MOS and MPS) depend on various factors; such as, the surface preparation or manufacture processes, the formation of interlayer which is native or deposited, its permittivity and homogeneity, the nature of barrier height, surface states, series resistance, bias voltage, device temperature and donor $\left(N_{D}\right)$ or acceptor atoms' $\left(N_{A}\right)$ doping concentration (Card and Rhoderick, 1971; Sze, 1981; Cheung and Cheung, 1986; Bohlin, 1986; Rhoderick and Williams, 1988; Tung, 2001; Tung, 2001; Tataroglu, 2013). The formation of an oxide or insulating interlayer such as $\mathrm{SiO}_{2}$ or $\mathrm{SnO}_{2}$ between metal and semiconductor by traditional methods is insufficient to reduce the leakage currents in the reverse bias region and formation of $N_{s s}$ with dislocations between interlayer and semiconductor with energies in the forbidden bandgap of the semiconductor. Therefore, some polymers undoped or doped with, for example $\mathrm{Ni}, \mathrm{Zn}, \mathrm{Co}$, graphene, have begun to be used instead of oxide materials due to their low cost, easy production techniques, flexibility and low weight per molecule (Demirezen et al., 2013; Guçlu et al., 2016; Akhlaghi et al., 2018; Badali et al., 2018; Altindal Yeriskin, 2019).

Both poly-vinyl-pyrorlidone (PVP) and poly-vinylalcohol (PVA) are semi-crystalline, watersoluble and have low conductivity, wide range crystallinity, high dielectric strength, good charge storage capacity, interesting physical and chemical properties which arise from $\mathrm{OH}$ groups and formation of hydrogen bonding (Lee et al. 2004). When polymers compared with semiconductors, they have low carrier mobility and dielectric constant, but this problem can be overcome by using a suitable dopant metal/graphene (Kaya et al. 2016; Altindal Yerişkin et al. 2017). For example, Altindal Yerişkin et al. 2017 have investigated the effects of (Gr-doped PVA) interfacial layer on Au/n-Si (MS) type structure by using various concentrations of graphene $(\% 0,1,3,5,7,10)$ and they showed that $\mathrm{Au} /(0.07 \mathrm{Gr}$ PVA)/n-Si (MPS) has lower $\mathrm{R}_{\mathrm{s}}$ and $\mathrm{N}_{\mathrm{ss}}$, higher $\mathrm{R}_{\mathrm{sh}}$ and $\mathrm{RR}$ with considerable increase of dielectric constant compared to a traditional MS structure with an insulator/oxide (MIS or MOS). They showed that the value of RR of MPS structure is about 500 times higher and $\mathrm{N}_{\mathrm{ss}}$ is about 95 times lower than the MS structure. Kaya et al. 2016 also showed that the value of $\varepsilon$ ' for (GO-doped PrBaCoO) the nanoceramic at $1 \mathrm{kHz}$ is almost 200 times higher than the conventional $\mathrm{SiO}_{2}$ and 15 times higher than $\mathrm{TiO}_{2}$.

Organic/polymer materials have also large surface area to volume rate, energy/charge storage capacity with much mechanical and dielectrical strength. Moreover, they are soluble in water and easily grown on the surface of a semiconductor. Thus, some polymer materials such as polyvinyl alcohol (PVA) and PVP can be grown as an interfacial layer between metal and semiconductor. These attractive properties lead to this study and MPS type SBDs were manufactured; then, with forward and reverse bias $I-V$ measurements in the wide bias voltage range $( \pm 3 \mathrm{~V})$, the electrical parameters were derived to determine the effect of (NiS doped PVP) polymer interlayer with voltage dependent characteristics of these electrical parameters. By using the forward bias $I-V$ data with $\Phi_{B}(V)$ and $n$, the $N_{s s}$ dependence on the energy levels was evaluated.

\section{MATERIALS AND METHODS}

The MPS type SBDs were grown on n-type (phosphorus-doped) Si wafer with $300 \mu \mathrm{m}$ thick and $1 \Omega \mathrm{cm}$ resistivity. First, it was cleaned in $\mathrm{H}_{2} \mathrm{O}, \mathrm{H}_{2} \mathrm{O}_{2}$, and $\mathrm{NH}_{4} \mathrm{OH}(3: 1: 1)$ solution at $70{ }^{\circ} \mathrm{C}$ in the ultrasonic bath and then rinsed in the ionized water at prolonged time and then rinsed in deionize water with high resistivity for $10 \mathrm{~min}$ and dried by dry nitrogen gas $\left(\mathrm{N}_{2}\right)$ to clean any oxidation. Second, ohmic contact with high-purity Au (99.999\%) with $1500 \AA$ A thick was thermally evaporated on the back side of 
the Si wafer at $10^{-6}$ Torr and then it was annealed at $500{ }^{\circ} \mathrm{C}$ in the nitrogenic atmosphere for 5 min to get a low resistivity ohmic contact. $0.2 \mathrm{M}$ from nickel chloride $6 \mathrm{H}_{2} \mathrm{O}\left(\mathrm{NiCl}_{2}, \mathrm{KBR}\right)$ was dissolved in $40 \mathrm{ml}$ distilled water and was stirred for $30 \mathrm{~min}$, then $0.5 \mathrm{M} \mathrm{Na} 2 \mathrm{~S} .3 \mathrm{H}_{2} \mathrm{O}$ (LOBA Chemie) was added to the solution drop by drop, until the $\mathrm{pH}$ of the solution is 7.0. Then, by adding $0.5 \mathrm{M} \mathrm{NaOH}$ (Merck), the reserved $\mathrm{pH}$ is 14 . Next, the sample is kept $15 \mathrm{~min}$ in Power $=180$ microwave device (SAMSUNG). The sample was washed 5 times with water and was dried in oven for $48 \mathrm{~h}$. Then, it was annealed at 1000 ${ }^{\circ} \mathrm{C}$. The prepared (NiS-PVP) composite was grown on the front side of the wafer by spin coating method. The thickness of (NiS-PVP) polymer interfacial layer was estimated to be $40 \mathrm{~nm}$. Circular shaped Au Schottky dot contacts with $7.85 \times 10^{-3} \mathrm{~cm}^{2}$ area and $1500 \AA$ thick were formed on the polymer layer at 10 ${ }^{-6}$ Torr. $I-V$ measurements were performed by the use of Keithley 2400 current/voltage source-meter in wide range of bias voltage $( \pm 3 \mathrm{~V})$ at room temperature.

\section{RESULTS AND DISCUSSION}

The semilogarithmic forward and reverse bias $I-V$ graph of the Au/(NiS-PVP)/n-Si (MPS) type SBD is given in Figure 1 to determine the effect of the (NiS-PVP) polymer layer at room temperature. In this figure, semilogarithmic $I-V$ plot of the MPS type SBD represents a satisfactory rectifier behaviour, i.e. while the value of the current in the reverse bias region becomes almost independent of reverse bias voltage, it has two different linear parts in the forward bias region with different slopes which correspond to low $(0.288 \leq \mathrm{V} \leq 0.625 \mathrm{~V})$ and moderate $(0.672 \leq \mathrm{V} \leq 0.960 \mathrm{~V})$ bias regions. By the effects of $R s$ and interfacial polymer layer, the linearity of the $I-V$ curve deviates in the high voltage region. This type of $I-V$ relation with two different linear parts in the forward bias region is explained with "two parallel diode model" in literature and the current mechanism in the MIS and MS type diodes is defined by utilizing the thermionic emission (TE) theory ( $V \geq 3 k T / q$ where $k$ is Boltzmann constant, $T$ is temperature and $q$ is electric charge) (Bohlin, 1986).

As shown in Figure 1, due to the two linear regions the "two-parallel diode model" can be recalled and the double exponential current equation with different barrier heights $(\mathrm{BH})$ and resistances is written as follows (Demirezen et al., 2013; Guclu et al., 2016):

$$
I=I_{01}\left[\exp \left(\frac{q\left(V-I R_{S}\right)}{n_{1} k T}\right)-1\right]+I_{02}\left[\exp \left(\frac{q\left(V-I R_{S}\right)}{n_{2} k T}\right)-1\right]+\frac{\left(V-I R_{S}\right)}{R_{S h}}
$$

Here $I_{01}$ and $I_{02}$ are the reverse saturation currents, $n_{1}$ and $n_{2}$ are the ideality factors for the low and moderate voltages and last term is the leakage current at very low voltages $(\leq 3 k T / q) . \Phi_{B_{0}}$ and $n(V)$ can be calculated for the two linear parts of $\ln I-V$ graph by the use of the following relations (Card, Rhoderick, 1971; Sze, 1981):

$$
\begin{aligned}
& I_{0}=A A^{*} T^{2} \exp \left(-\frac{q \Phi_{B_{0}}}{k T}\right) \\
& \Phi_{B_{0}}=\frac{k T}{q} \ln \left(\frac{A A^{*} T^{2}}{I_{0}}\right) \\
& n(V)=\frac{q}{k T}\left(\frac{d V}{d(\operatorname{InI} I)}\right)=1+\frac{\delta}{\varepsilon_{i}}\left[\frac{\varepsilon_{S}}{W_{D}}+q N_{S S}(V)\right]
\end{aligned}
$$


In Equation (2a), (2b) and (3), $A$ is $7.85 \times 10^{-3} \mathrm{~cm}^{2}, A^{*}$ is the Richardson constant $\left(112 \mathrm{Acm}^{-2} \mathrm{~K}^{-2}\right.$ for $\mathrm{n}-\mathrm{Si})$. Thus, the main electrical parameters $\left(I_{0}, n, \Phi_{B_{0}}\right)$ of SBD were calculated as $1.20 \times 10^{-8} \mathrm{~A}, 7.23$, and $0.683 \mathrm{eV}$ for low bias region and $3.20 \times 10^{-9} \mathrm{~A}, 4.23$ and $0.732 \mathrm{eV}$ for moderate bias region, respectively. The ideal value of $n$ which indicates conformity to TE theory and values higher than the ideal value for the two linear region of $\ln I-V$ plot indicate deviation from TE theory. Such higher values of $n$ are ascribed by the existence of (NiS-PVP) polymer interlayer, $N_{s s}$ and inhomogeneities of the barrier between semiconductor and metal (Guttler and Werner, 1990; Schmitsdorf et al., 1995; Hudait et al., 2001; Orak and Kocyigit, 2016; Alptekin and Altindal, 2019). The high value of $n$ usually stems from the existence of interfacial layer, its thickness $\left(\mathrm{d}_{\mathrm{i}}\right)$, homogeneity and permittivity $\left(\varepsilon_{\mathrm{i}}\right)$, barrier inhomogeneity at $\mathrm{M} / \mathrm{S}$ interface, $\mathrm{N}_{\mathrm{ss}}$, and doping concentration atoms in semiconductor or depletion layer width $\left(\mathrm{W}_{\mathrm{d}}\right)$ as given in Equation (3). The tunneling through the barrier via surface states or dislocations, recombination-generation, and image-force lowering also affect the ideality factor and the conduction mechanism (CM) (Card and Rhoderick, 1971; Sze, 1981).

Both the forward and the reverse bias semi-logarithmic $I-V$ plots for both the Au/n-Si (MS) and $\mathrm{Au} /(\mathrm{NiS}-\mathrm{PVP}) / \mathrm{n}-\mathrm{Si} / \mathrm{Au}$ devices were drawn and given in Figure 1 to see the effects of (NiS-PVP) polymer interlayer on the $I-V$ characteristics. As can be seen in Figure $1, \mathrm{RR}$ at $\pm 3 \mathrm{~V}$ for the MPS structure is almost 10 times higher than the MS structure. In addition, while the forward bias semilogarithmic I-V plot has only one linear region for MS structure, this plot for MPS structure has two distinctive linear regions with different slopes. In other words, such two linear behaviours for MPS structure are called as double exponential model or two-parallel diodes model with different $R_{S}$ and $\Phi_{B_{0}}$. As it is also seen in Figure 1, (NiS-PVP) interfacial polymer layer leads to a decrease in reverse current at about 10 times when compared with the MS structure. All these results show that the used (NiS-PVP) polymer interlayer leads to improve the performance of MS and hence, can successfully be used instead of conventional $\mathrm{SiO}_{2}$ interlayer due to its low cost, easy preparation processes, flexibility and high dielectric/mechanical strength.

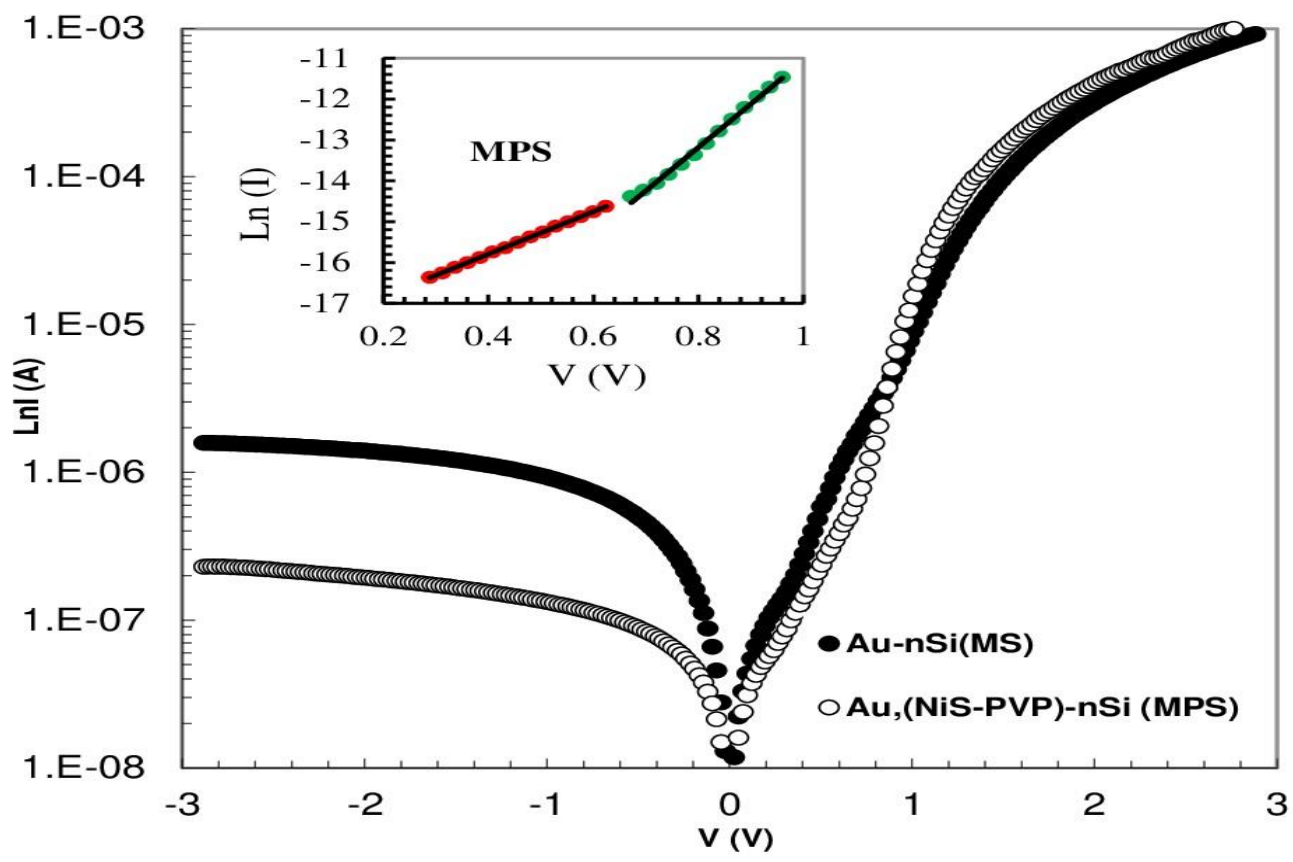

Figure 1. The ln $I-V$ plot of the Au/n-Si (MS) and Au/(NiS-PVP)/n-Si (MPS) SBDs at room temperature. Inset shows the linear fits of the low and moderate voltage region 
$R_{s}$ and $R_{s h}$ are more effective on the electrical characteristics, so they can cause serious errors in the calculations. The existence of $R_{S}$ leads to serious error in the extraction of basic electrical parameters and conduction mechanisms of the MS structure with and without an interfacial layer. Usually, $R_{S}$ can arise from four different sources: (i) the contact made by the probe wire to the rectifier contact; (ii) the back ohmic contact to the semiconductor; (iii) the resistance of the bulk semiconductor; (iv) inhomogeneous doping concentration of donor or acceptor atoms in the semiconductor (Nicollian and Brews, 1982). Therefore, the resistance of the diode structure $\left(R_{i}\right)$ with respect to varying voltage is plotted with respect to Ohm's Law $\left(R_{i}=\mathrm{d} V_{i} / \mathrm{d} I_{i}\right)$ and is given in Figure 2. The value of $R_{i}$ proceeds constant both in the enough high forward and reverse bias region, shown in Figure 2. Therefore, the real value of $R_{s}$ and $R_{s h}$ for the MPS type SBD correspond to high forward and high reverse bias regions and they are found as $0.6 \mathrm{k} \Omega$ and $13 \mathrm{M} \Omega$ for $( \pm 3 \mathrm{~V})$, respectively. RR of the diode is calculated at about $10^{4}$, which is a satisfactory rectifier property. All these obtained experimental electrical parameters from the $I$ - $V$ characteristics $\left(I_{0}, n, \Phi_{B_{0}}, R_{S}\right.$ and $\left.R_{s h}\right)$ are also tabulated in Table 1.

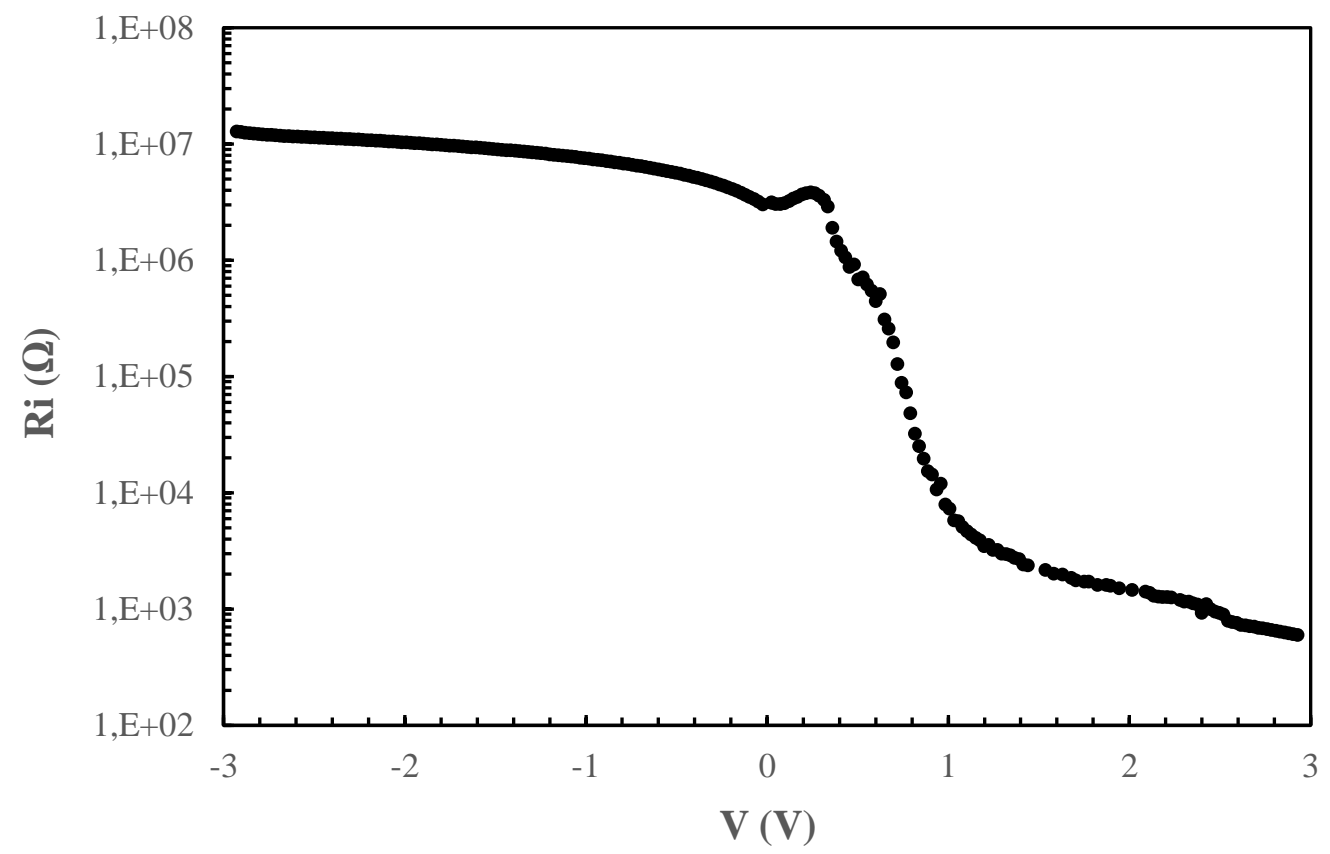

Figure 2. The $R_{i^{-}} V$ plot of the Au/(NiS-PVP)/n-Si (MPS) SBD at room temperature.

Table 1. The obtained some main experimental electrical parameters of the Au/(NiS-PVP)/n-Si (MPS) SBD from the $I-V$ data at room temperature.

\begin{tabular}{|c|c|c|c|c|c|c|}
\hline $\begin{array}{l}\text { Voltage } \\
\text { Region }\end{array}$ & $I_{0}(\mathrm{~A})$ & $n$ & $\Phi_{B o}(\mathrm{eV})$ & $\begin{array}{l}R_{S}(\text { at } 3 V) \\
(\mathrm{k} \Omega)\end{array}$ & $\begin{array}{l}R_{s h}(\text { at }-3 V) \\
(\mathrm{M} \Omega)\end{array}$ & $\begin{array}{l}\text { Mean value of } \\
N_{s s}\left(\mathrm{eV}^{-1} \mathbf{c m}^{-2}\right)\end{array}$ \\
\hline Low & $1.20 \times 10^{-8}$ & 7.23 & 0.683 & \multirow{2}{*}{0.60} & \multirow{2}{*}{13.0} & \multirow{2}{*}{$7.0 \times 10^{12}$} \\
\hline Moderate & $3.20 \times 10^{-9}$ & 4.23 & 0.732 & & & \\
\hline
\end{tabular}

In addition, values of the basic electrical parameters $\left(R_{s}, n\right.$ and $\left.\Phi_{B}\right)$ of the diode can be obtained from the Cheung functions as another way by using the equations (Cheung and Cheung, 1986):

$$
\frac{\mathrm{d} V}{\mathrm{~d}(\operatorname{In} I)}=I R_{S}+\left(\frac{n k T}{q}\right)
$$


$\mathrm{H}(I)=V-\frac{n k T}{q} \operatorname{In}\left(\frac{I}{A A^{*} T^{2}}\right)=I R_{S}+n \Phi_{B_{0}}$

The $\mathrm{d} V / \mathrm{d} \ln (I)$ and $\mathrm{H}(I)$ versus current plots were calculated from Equation (4a) and (4b), respectively, and represented in Figure 3. As can be clearly seen in Figure 3 (a) and (b), both the $d V /$ $\mathrm{dln}(I)$ vs $I$ and $\mathrm{H}(I)$ vs $I$ plots have a good linear representation in the enough high forward bias voltage which corresponds to concave curvature of the $\ln I$ vs $V$ plot. Firstly, the value of $R_{s}$ is found from the slope of $\mathrm{d} V / \mathrm{d} \ln (I)$ vs $I$ and $\mathrm{H}(I)$ vs $I$ plots in the same current range as $1.063 \mathrm{k} \Omega$ and $0.989 \mathrm{k} \Omega$, respectively and these values are closer to the values obtained from Ohm's Law at room temperature. The value of ideality factor is found as 10.92 from the intercept of $\mathrm{d} V / \mathrm{dln}(I)$ vs $I$ plot using Equation (4a). Thus, by using this value of $n, \Phi_{B}$ is found $0.64 \mathrm{eV}$ from the intercept of $\mathrm{H}(I)$ vs $I$ graph by using Equation (4b). The observed discrepancies in the calculated basic electrical parameters $\left(R_{s}, n, \Phi_{B}\right)$ are attributed to the calculation method that corresponds to different voltage range (Bohlin, 1986; Cheung and Cheung, 1986; Tataroglu, 2013).

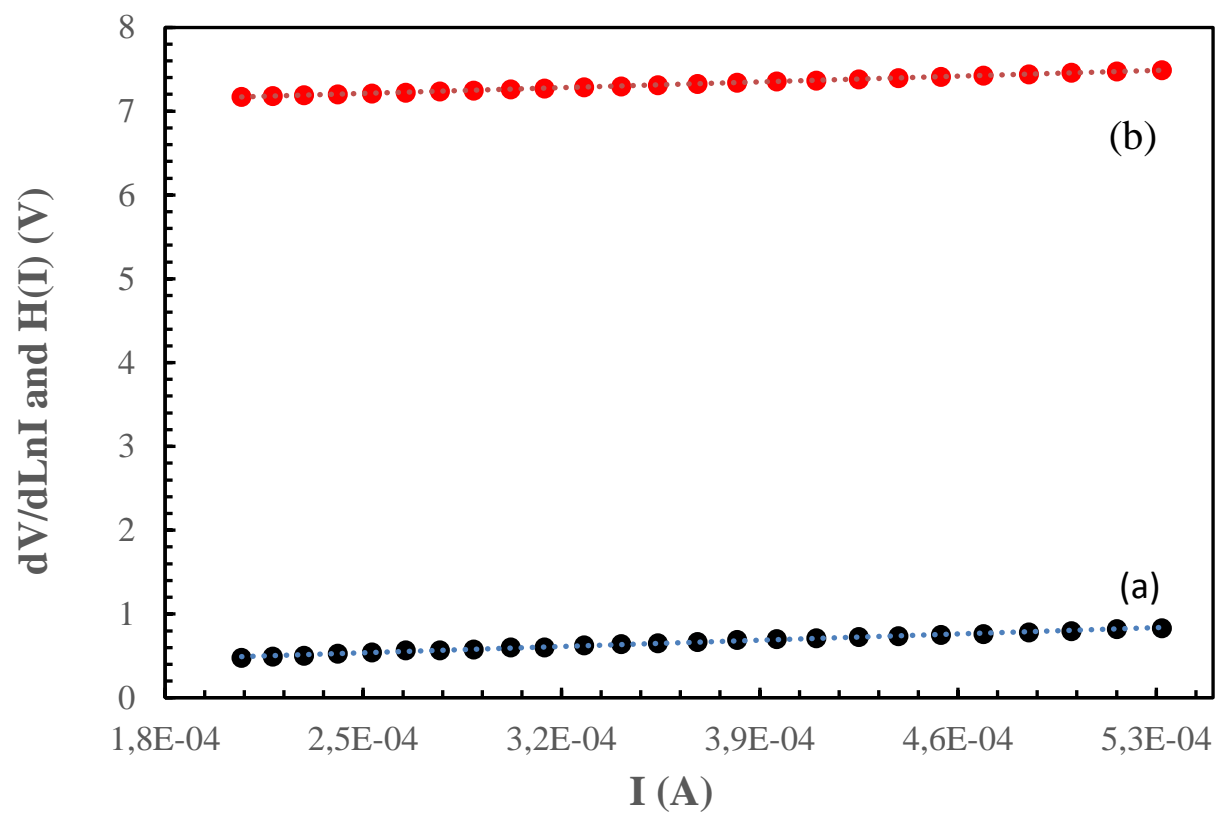

Figure 3. The $\mathrm{d} V / \mathrm{d} \ln I$ (a) and $\mathrm{H}(I)$ (b) vs $I$ plots for Au/(NiS-PVP)/n-Si (MPS) SBD at room temperature

The effect of voltage on the basic electrical parameters of SBDs is very important to detect the working capacity of the device. Therefore, the value of $\Phi_{\mathrm{B}}(V)$ is also obtained as a function of forward bias $I-V$ data except $\Phi_{B o}$ and is given in Figure 4. As can be seen in Figure 4, the value of the BH decreases with increasing applied bias voltage and it is changed from $0.714 \mathrm{eV}$ at $0.1 \mathrm{~V}$ to $0.450 \mathrm{eV}$ at 3 $\mathrm{V}$, due to the effect of image force-lowering, $R_{s}$ of the SBD and interfacial polymer layer. The effect of $R_{s}$ and interfacial layer is considerably so high that the applied bias voltage is degraded by the depletion layer.

Many surface states and dislocations may be occurred with energies located in the forbidden bandgap of semiconductor $\left(\mathrm{E}_{\mathrm{g}}\right)$ at layer/semiconductor interface, even though the diodes are fabricated in clean condition and they can considerably affect the performance of the devices. These states or traps are usually originated from defects such as dangling bonds in the interlayer/semiconductor interface with 
energy states in the band gap $\left(E_{\mathrm{g}}\right)$, unsaturated dangling bonds, some contaminating organic impurities in the laboratory environment and the chemical composition of the interface.

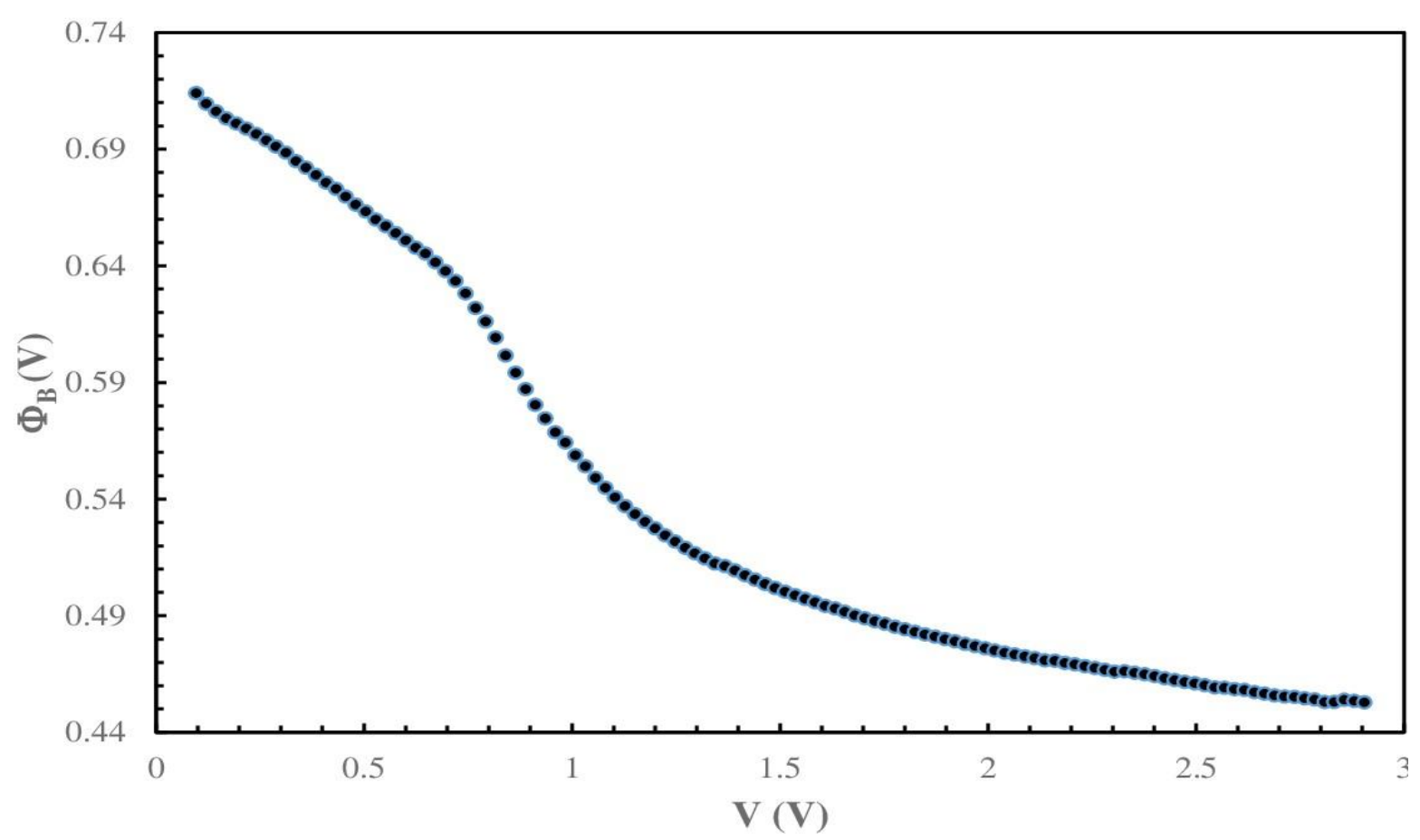

Figure 4. The voltage dependent barrier height of the Au/(NiS-PVP)/n-Si (MPS) SBD at room temperature

The energies of these states are usually in equilibrium with the semiconductor band structure rather than the metal when the interfacial layer thickness is higher than at about $\sim 3 \mathrm{~nm}$ (Card and Rhoderick, $1971)$. These states are effective on the electrical parameters; thus, $N_{s s}$ vs $\left(E_{c}-E_{s s}\right)$ profile is obtained by the use of $\Phi_{\mathrm{B}}(V)$ and $n$ at room temperature and is given in Figure 5 by using the following relations (Card and Rhoderick, 1971; Sze, 1981; Rhoderick and Williams, 1988; Tung, 2001; Tataroglu, 2013), where $E_{c}$ and $E_{s s}$ are the energies of the conduction band and the surface states, respectively:

$\mathrm{n}(V)=\frac{q V_{d}}{k T \ln \left(I / I_{0}\right)}$

$E_{c}-E_{S S}=q\left(\Phi_{e}-V_{i}\right)$

$\Phi_{e}-\Phi_{\mathrm{B}_{0}}=\left(1-\frac{1}{n(V)}\right) V$

$N_{S S}=\frac{\varepsilon_{0}}{q}\left\{\frac{\varepsilon_{i}}{d}[n(V)-1]-\frac{\varepsilon_{S}}{W_{D}}\right\}$

In Equation (6), $d$ is the interfacial polymer layer thickness, $W_{D}$ is the depletion layer width, $\varepsilon_{i}$, $\varepsilon_{s}$ and $\varepsilon_{0}$ are dielectric values of the polymer interlayer, the semiconductor and the vacuum, respectively.

In Figure 5, the energy dependent profile of $N_{s s}$ behaves like U-shape and the indicates that $N_{s s}$ starts to increase from the center of the bandgap of Si to the bottom of the conduction band. The mean value of $N_{s s}$ is found as $7.0 \times 10^{12} \mathrm{eV}^{-1} \mathrm{~cm}^{-2}$ and they are considerably acceptable for the MPS type 
structure. As a result, it can be said that the used (NiS-PVP) polymer interface between Au and n-Si wafer leads to an increase in the performance of MS. The investigation of interfacial layer effects on the electrical and performance of the MS structures were also investigated in very recently and they also obtained similar results (Orak and Kocyigit, 2016; Ulusan et al., 2019; Tataroglu et al., 2020; Eroglu et al., 2020).

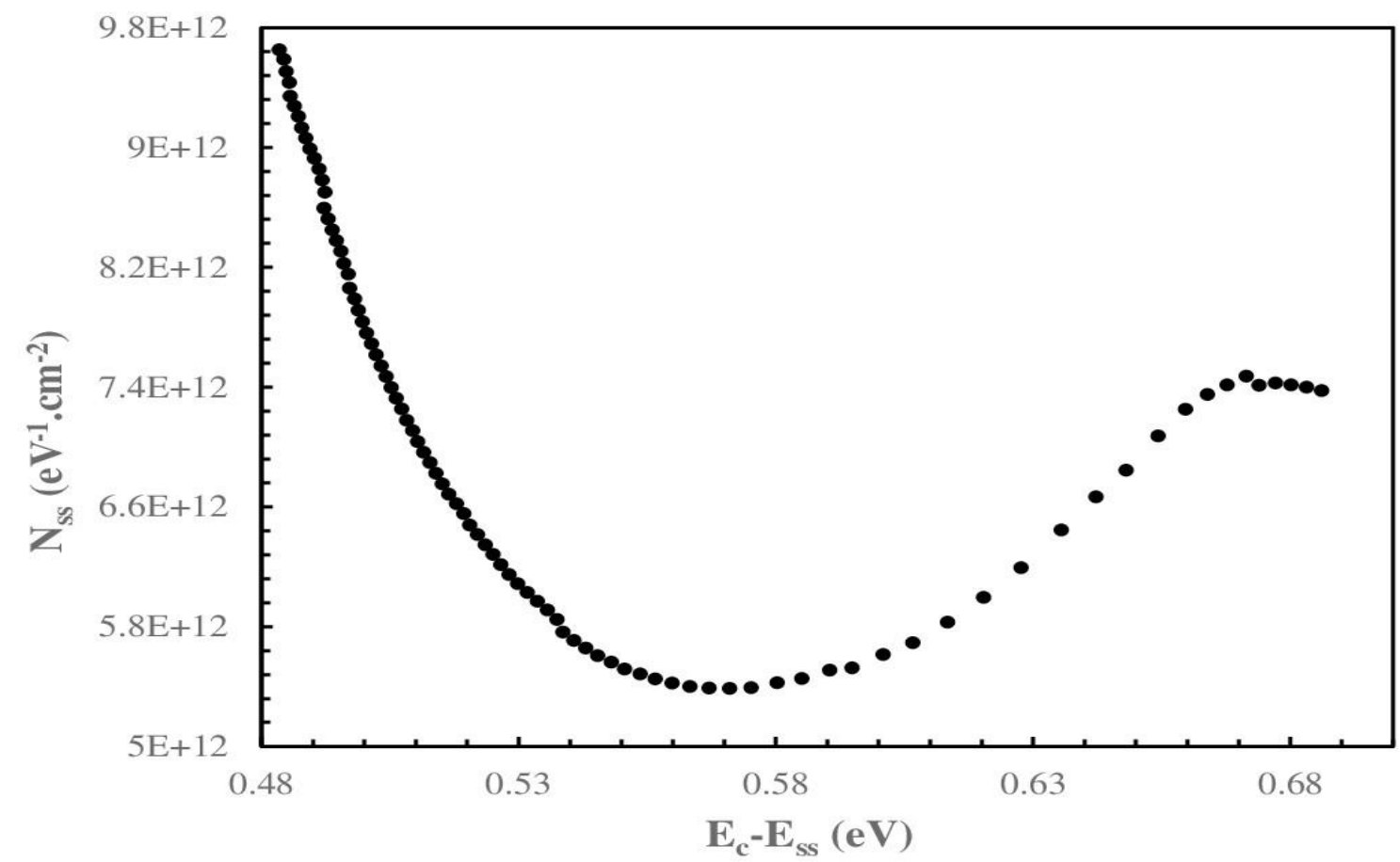

Figure 5. The energy dependent profile of $N_{s s}$ for $\mathrm{Au} /(\mathrm{NiS}-\mathrm{PVP}) / \mathrm{n}-\mathrm{Si}$ (MPS) SBD at room temperature

\section{CONCLUSION}

$\mathrm{Au} / \mathrm{n}-\mathrm{Si}$ (NiS doped-PVP) SBD with polymer interlayer grown by electrospinning technique is used to determine the effects of interfacial layer and bias voltage on the electrical characteristics. Main electrical parameters $\left(\mathrm{I}_{0}, \Phi_{B_{0}}, R R, n, R_{s}\right.$ and $\left.R_{s h}\right)$ are obtained at room temperature by using forward and reverse bias $I-V$ characteristics in the voltage range of $( \pm 3 \mathrm{~V})$. The forward bias $\ln I-V$ plot of the MPS type SBD represents a good rectifier behaviour and it has two linear regimes with different slopes between $(0.288 \leq \mathrm{V} \leq 0.625 \mathrm{~V})$ and $(0.672 \leq \mathrm{V} \leq 0.960 \mathrm{~V})$ bias voltages. But it deviates from linearity because of $R_{s}$ and interfacial polymer layer at enough high bias voltages (V $\left.\geq 1 \mathrm{~V}\right) . N_{s s}$ vs $\left(E c-E_{s s}\right)$ profile is obtained by the use of $\Phi_{B}$ and $n$. The mean value of $N_{s s}$ is calculated as $7 \times 0^{12} \mathrm{eV}^{-1} \mathrm{~cm}^{-2}$. Moreover, such lower values of $N_{s s}$ can be attributed to the passivation effect on the surface states. The obtained experimental results indicate that $R_{s}$ and $N_{s s}$, interfacial layer and bias voltage are very effective on the electrical behaviour of the device, which must be taken into consideration in the calculations to get more precise and reliable results on electrical features and conduction mechanisms.

\section{ACKNOWLEDGEMENTS}

This research is supported by Gazi University Scientific Research Project. (Project Number: GUBAP.05/2019-26).

\section{Conflict of Interest}

I declare that there is no conflict of interest during the planning, execution and writing of the article. 


\section{Author's Contilbutions}

I hereby declare that the planning, execution and writing of the article was done by me as the sole author of the article.

\section{REFERENCES}

Akhlaghi EA, Badali Y, Altindal S, Azizian-Kalandaragh Y, 2018. Preparation of mixed Copper/PVA nanocomposites as an interface layer for fabrication of $\mathrm{Al} / \mathrm{Cu}-\mathrm{PVA} / \mathrm{p}-\mathrm{Si}$ Schottky structures. Physica B-Condensed Matter, 546: 93-98.

Alptekin S, Altindal S, 2019. Comparative study on current/capacitance: Voltage characteristics of Au/nSi (MS) structures with and without PVP interlayer. Journal of Materials Science: Materials in Electronics, 30: 6491-6499.

Altindal Yeriskin S, Balbaşi M, Orak I, 2017. The effects of (graphene doped-PVA) interlayer on the determinative electrical parameters of the $\mathrm{Au} / \mathrm{n}-\mathrm{Si}$ (MS) structures at room temperature. Journal of Material Science: Material Electronics, 28: 14040-14048.

Altindal Yerişkin S, 2019. The investiagtion of effects of $\left(\mathrm{Fe}_{2} \mathrm{O}_{4}-\mathrm{PVP}\right)$ organic interlayer, surface states, and series resistance on the electrical characteristics and sources of them. Journal of Materials Science Materials in Electronics, 30: 17032-17039.

Badali Y, Nikravan A, Altindal S, Uslu I, 2018. Effects of a thin Ru-doped PVP interface layer on electrical behaviour of Ag/n-Si structures. Journal of Electronic Materials, 47: 3510-3520.

Bohlin KE, 1986. Generalized Norde plot including determination of the ideality factor. Journal of Applied Physics, 60: 1223.

Card HC, Rhoderick EH, 1971. Studies of tunnel MOS diodes I. Interface effects in silicon Schottky diodes. Journal of Physics D: Applied Physics, 4: 1589-1601.

Cheung SK, Cheung NW, 1986. Extraction of Schottky diode parameters from forward current-voltage characteristics. Applied Physics Letters, 49: 85.

Demirezen S, Altindal S, Uslu I, 2013. Two diodes model and illumination effect on the forward and reverse bias $\mathrm{I}-\mathrm{V}$ and $\mathrm{C}-\mathrm{V}$ characteristics of $\mathrm{Au} /(\mathrm{PVA})(\mathrm{Bi}-\mathrm{doped}) / \mathrm{n}-\mathrm{Si}$ photodiode at room temperature. Current Applied Physics, 13: 53-59.

Eroglu A, Demirezen S, Kalandaragh YA, Altindal S, 2020. A comparative study on the electrical properties and conduction mechanisms of $\mathrm{Au} / \mathrm{n}-\mathrm{Si}$ Schottky diodes with/without an organic interlayer. Journal of Materials Science: Materials in Electronics 31: 14466-14477.

Guçlu CS, Ozdemir AF, Altindal S, 2016. Double exponential I-V characteristics and double gaussian distribution of barrier heights in ( $\mathrm{Au} / \mathrm{Ti}) / \mathrm{Al}_{2} \mathrm{O}_{3} / \mathrm{n}-\mathrm{GaAs}$ (MIS)-type Schottky barrier diodes in wide temperature range. Applied Physics A, 122: 1032.

Guttler HH, Werner JH, 1990. Influence of barrier inhomogeneities on noise at Schottky contacts. Applied Physics Letters, 56: 1113-1115.

Hudait MK, Venkateswarlu KP, Krupanidhi SB, 2001. Electrical transport characteristics of Au/n-GaAs Schottky diodes on n-Ge at low temperatures. Solid-State Electronics, 45: 133-141.

Kaya A, Alialy S, Demirezen S, Balbaşi M, Altindal Yerişkin S, Aytimur A, 2016. The investigation of dielectric properties and ac conductivity of $\mathrm{Au} / \mathrm{GO}$-doped $\mathrm{PrBaCoO}$ nanoceramic/n-Si capacitors using impedance spectroscopy method. Ceramics International, 42: 3322-3329.

Lee JS, Choi KH, Ghim HD, Kim SS, Chun DH, Kim HY, Lyoo WS, 2004. Role of molecular weight of atactic poly(vinyl alcohol) (PVA) in the structure and properties of PVA nanofabric prepared by electrospinning, Journal of Applied Polymer Science. 93: 1638-1646. 
Nicollian EH, Brews JR, 1982. MOS (Metal Oxide Semiconductor) Physics and Technology, Wiley, New York.

Orak I, Kocyigit A, 2016. The electrical characterization effect of insulator layer between semiconductor and metal. Igdir University Journal of the Institute of Science and Technology, 6: 57-67.

Rhoderick EH, Williams RH, 1988. Metal Semiconductor Contacts. Second Edition, Oxford. 257-267.

Schmitsdorf RF, Kampen TU, Monch W, 1995. Correlation between barrier height and interface structure of Ag/ Si (111) Schottky diodes. Surface Science, 324: 249-256.

Sze SM, 1981. Physics of Semiconductor Devices. Second Edition, New York, 362-380.

Tataroglu A, 2013. Comparative study of the electrical properties of Au/n-Si (MS) and $\mathrm{Au} / \mathrm{Si}_{3} \mathrm{~N}_{4} / \mathrm{n}-\mathrm{Si}$ (MIS) Schottky diodes. Chinese Physics B, 22: 068402.

Tataroglu A, Altindal S, Kalandaragh YA, 2020. Comparison of electrical properties of MS and MPS type diodes in respect of $\left(\operatorname{In}_{2} \mathrm{O}_{3}-\mathrm{PVP}\right)$ interlayer. Physica B, 576: 411733.

Tung RT, 2001. Formation of an electric dipole at metal-semiconductor interfaces. Physical Review B, 64: 205310.

Tung RT, 2001. Recent advances in Schottky barrier concepts. Material Science and Engineering RReports, 35: 1.

Ulusan AB, Tascioglu İ, Tataroglu A, Yakuphanoglu F, Altindal S, 2019. A comparative study on the electrical and dielectric properties of $\mathrm{Al} / \mathrm{Cd}$-doped $\mathrm{ZnO} / \mathrm{p}-\mathrm{Si}$ structures. Journal of Materials Science: Materials in Electronics, 30: 12122-12129. 